\title{
Buckling response of ferritic stainless steel columns at elevated temperatures
}

\author{
S. Afshan \& L. Gardner \\ Imperial College London, London, UK \\ N. R. Baddoo \\ The Steel Construction Institute, Ascot, UK
}

\begin{abstract}
This paper presents a numerical study on the buckling behaviour of ferritic stainless steel columns in fire. Finite element models were developed and validated against existing test results to predict the elevated temperature non-linear response of ferritic stainless steel columns. A total of nine austenitic and three ferritic stainless steel column tests were replicated using the finite element analysis package ABAQUS. Parametric studies were performed to investigate the effects of variation of load level and global slenderness on the elevated temperature buckling response of ferritic stainless steel columns, and to extend the range of structural performance data. Both the experimental and numerical parametric study results were compared with the current design rules in EN 1993-1-2 (2005) and recent proposed modifications thereof by $\mathrm{Ng}$ and Gardner (2007), Uppfeldt et al. (2008) and Lopes et al. (2010).
\end{abstract}

\section{INTRODUCTION}

The characteristics of stainless steel, such as inherent durability, good mechanical properties and ease of maintenance, make it ideally suited for many civil engineering applications. Austenitic stainless steels, containing $17-18 \%$ chromium and $8-11 \%$ nickel, are the most widely used grades. However, the price of the alloying elements, in particular nickel, represents a major disincentive as far as material selection is concerned.

Hence, stainless steel grades with chemical compositions that offer similar benefits to the austenitics, but with lower nickel content, have been developed. Ferritic stainless steels, with little or no nickel content, have found applications in the automotive industry, road and rail transport, power generation, and mining. However, ferritic stainless steels have scarcely been used in structural applications. The aim of this study is to explore the fire resistance of ferritic stainless steel columns and assess the suitability of the current design provisions to this family of stainless steel.

\section{REVIEW OF FIRE TESTS ON FERRITIC STAINLESS STEELS}

The Steel Construction Institute is co-ordinating an ongoing RFCS project called Structural Applications of Ferritic Stainless Steels (RFSR-CT-2010-00026). This project includes an investigation into the per- formance of ferritic stainless steel members in fire. Experimental studies, focusing on the buckling response of columns made of grade EN 1.4003 ferritic stainless steel in fire were carried out at the University of Liège (Rossi, 2013). Elevated temperature material tests were also conducted and are reported in Manninen and Säynäjäkanas (2012). These results are utilized herein for the development and validation of the numerical models.

\subsection{Material properties}

Isothermal tensile coupon tests on material cut from EN 1.4003 cold-rolled sheets were performed in the temperature range of $20-1000{ }^{\circ} \mathrm{C}$ (Manninen and Säynäjäkanas, 2012). Elevated temperature material properties are expressed as a portion of the corresponding room temperature properties. This leads to the use of strength and stiffness reduction factors for key parameters i.e. the elevated temperature $0.2 \%$ proof stress, ultimate tensile stress and Young's modulus. The stiffness retention factor $\mathrm{k}_{\mathrm{E}, \theta}$ is defined as the elevated temperature initial tangent modulus $\mathrm{E}_{\theta}$, normalized by the initial tangent modulus at room temperature $\mathrm{E}$. The strength retention factors $\mathrm{k}_{0.2, \theta}$ and $\mathrm{k}_{\mathrm{u}, \theta}$ are defined as the elevated temperature $0.2 \%$ proof stress and ultimate tensile stress normalized by their respective room temperature values. The $\mathrm{k}_{2, \theta}$ factor is also used for determining the material strength at $2 \%$ total strain $\sigma_{\mathrm{t} 2, \theta}$, as defined in Annex C of EN 1993-1-2 (2005). Figures 
1-2 show the measured reduction factors for the $0.2 \%$ proof stress and the ultimate tensile stress, respectively. The corresponding EN 1993-1-2 (2005) reduction factors for grade EN 1.4003 stainless steel and structural carbon steel are also depicted. EN 1993-1-2 (2005) provides a single set of stiffness reduction factors, common to all stainless steel grades. The test results obtained showed that in fact the elevated temperature stiffness of ferritic stainless steel (grade EN 1.4003) is somewhat in between that of the austenitics and structural carbon steel. The measured strength reduction factors are in good agreement with the EN 1.4003 codified values.

\subsection{Flexural buckling}

A total of three full scale fire tests on ferritic EN 1.4003 stainless steel tubular columns were conducted (Rossi, 2013). A summary of the test details, including nominal section size, specimen length, applied loads and critical furnace temperatures are provided in Tables 1 . All columns were fixed at both ends. The manufacturing process of the tested columns involved cold-rolling into a circular tube followed by sizing into the final cross-section geometry. All fire tests were performed anisothermally, whereby the load - taken as approximately $30 \%$ of the specimen's codified room temperature buckling resistance - was applied at room temperature and maintained at a constant level while the temperature was increased, following the standard ISO-834 (2002) fire curve, until failure.

Table 1. Summary of ferritic column fire tests.

\begin{tabular}{lccc}
\hline Nominal section size & $\begin{array}{c}\text { Length } \\
(\mathrm{mm})\end{array}$ & $\begin{array}{c}\text { Load } \\
(\mathrm{kN})\end{array}$ & $\begin{array}{c}\text { Critical furnace } \\
\text { Temperature }\left({ }^{\circ} \mathrm{C}\right)\end{array}$ \\
\hline SHS $80 \times 80 \times 3$ & 3000 & 72 & 709.4 \\
SHS $80 \times 80 \times 3$ & 2500 & 78 & 707.7 \\
RHS $120 \times 80 \times 3$ & 3000 & 100 & 705.0 \\
\hline
\end{tabular}

\section{NUMERICAL MODELLING}

The aim of this section is to develop and validate numerical models for predicting the resistance of stainless steel columns in fire. Fire test results from the literature on austenitic (EN 1.4301) stainless steel columns from Baddoo and Gardner (2000) and Ala-Outinen and Oksanen (1997) and ferritic stainless columns (Rossi, 2013) were gathered. These test results were used to validate the finite element models. The development of the numerical models leading into the results of parametric studies is described herein.

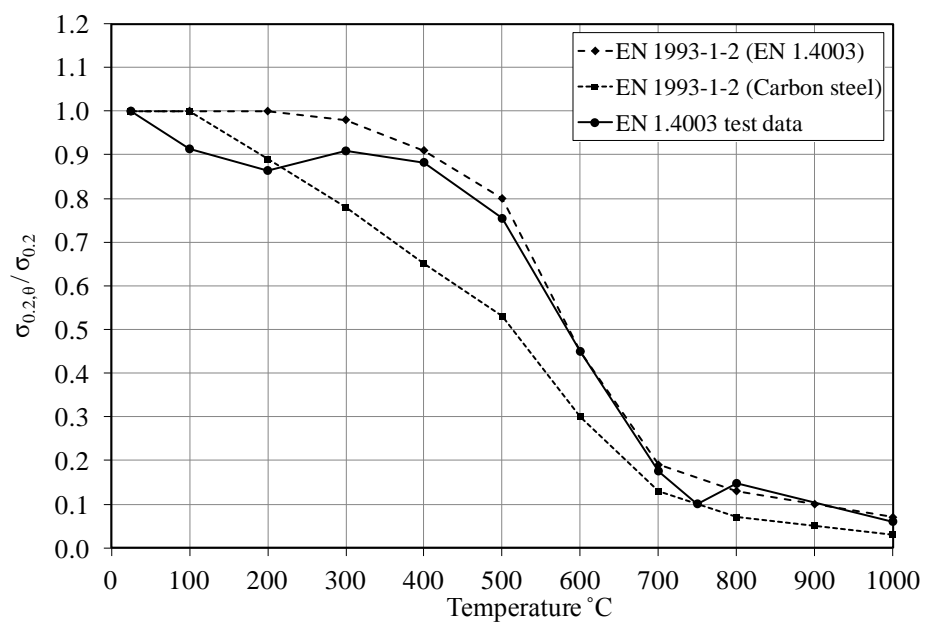

Figure $1.0 .2 \%$ proof stress reduction factor.

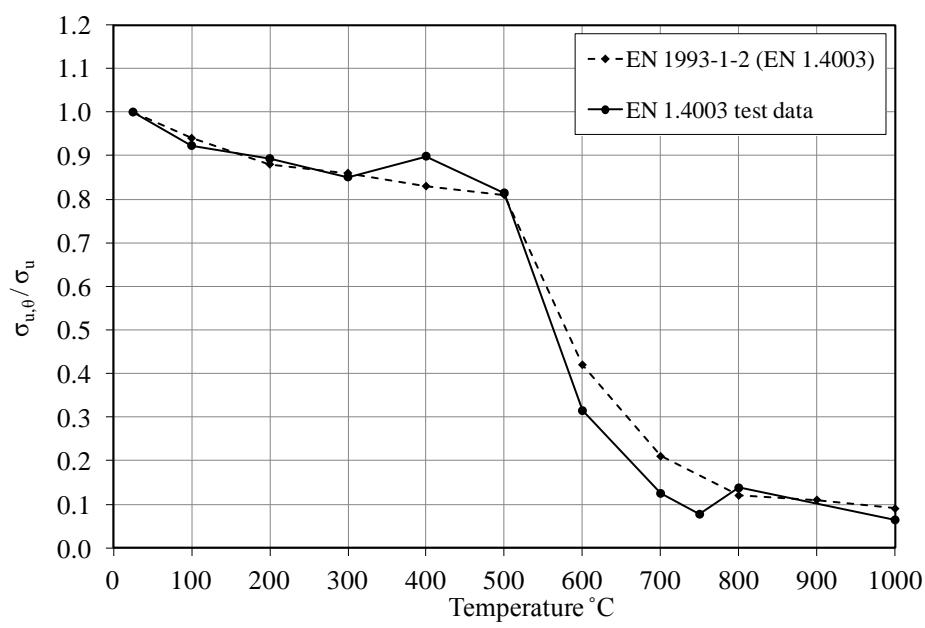

Figure 2. Ultimate tensile stress reduction factor.

\subsection{Validation of numerical models}

\subsubsection{General}

The non-linear finite element analysis package ABAQUS, Version 6.10-1 (2010) was used to replicate the elevated temperature response of column tests from the literature. Shell elements were adopted to simulate the stainless steel tubular hollow section columns as is customary for modelling of thin-walled structures. The four-node doubly curved general-purpose shell element with reduced integration S4R, for the structural model, and D4S, for the thermal model, which has performed well in numerous similar applications (e.g. Ng \& Gardner, 2007; To \& Young, 2008) were used. A suitable mesh size, providing accurate results with practical computational times, with a minimum of ten elements across each plate was adopted.

The test boundary conditions were replicated by restraining suitable displacement and rotation degrees of freedom at the column ends. All boundary conditions were applied through reference points at the column ends. For the fixed column tests, all the six degrees of freedom of the lower reference point were restrained, while the upper reference point was allowed to move along the column axis and was fixed against all the other five degrees of freedom. 
To model the pinned end support condition, all degrees of freedom of the lower reference point, except rotation about the column minor axis, were fixed, while the upper reference point was free to displace along the column axis and rotate about the column minor axis. Measured geometric dimensions were used in each model to replicate the corresponding test behaviour.

\subsubsection{Elevated temperature material properties}

The performance of finite element models is highly sensitive to the prescribed material parameters, hence making an accurate representation of the material characteristics essential. In Baddoo and Gardner (2000), isothermal material tests at temperatures $20-1000{ }^{\circ} \mathrm{C}$ were performed on the sheet material used to fabricate the stainless steel sections. AlaOutinen and Oksanen (1997) carried out anisothermal tensile tests on coupons cut from the flat faces of cold-rolled sections and the results were converted into stress-strain curves at temperatures 20 $900{ }^{\circ} \mathrm{C}$. The measured material stress-strain curves at elevated temperatures were utilised in the development of the finite element models. For the ferritic column tests, the material model proposed by Gardner et al. (2010), along with the measured elevated temperature reduction factors, provided in Section 2, and the room room temperature material properties were used. ABAQUS requires that the material properties are specified in terms of true stress $\sigma_{\text {true }}$ and $\log$ plastic strain $\varepsilon_{\ln }^{\mathrm{p}}$, which may be derived from the nominal engineering stress-strain curves as defined in Eqs. (1) and (2), respectively, where $\sigma_{\text {nom }}$ and $\varepsilon_{\text {nom }}$ are engineering stress and strain, respectively and $\mathrm{E}$ is the Young's modulus.

$\sigma_{\text {true }}=\sigma_{\text {nom }}\left(1+\varepsilon_{\text {nom }}\right)$

$\varepsilon_{\ln }^{\mathrm{p}}=\ln \left(1+\varepsilon_{\text {nom }}\right)-\frac{\sigma_{\text {true }}}{E}$

For austenitic stainless steel, the thermal properties from EN 1993-1-2 (2005) were incorporated in the models. The thermal properties of ferritic stainless steels are different from the austenitic stainless steels and are not covered in EN 1993-1-2 (2005). Thermal expansion data were sourced from EN 10088-1 (2005) and specific heat and thermal conductivity data were obtained from the StahlDat SX (2011) database.

\subsubsection{Corner material modelling}

Stainless steel exhibits a pronounced response to cold-work, resulting in the corner regions of coldformed sections having significantly higher $0.2 \%$ proof strengths than the flat faces. For the ferritic column tests, corner material properties were measured at room temperature. For the austenitic stainless steel tests, where no corner material properties were reported, Cruise and Gardner's (2008) predictive equations for the strength enhancement in the corner regions of cold-rolled and press-braked stainless steel sections were used to determine the room temperature $0.2 \%$ proof strength of the corner regions.

The modified compound Ramberg-Osgood material model proposed by Gardner et al. (2010) was used to obtain a continuous prediction of the stressstrain response of the cold-worked corner regions at elevated temperatures. It has been shown that the beneficial effect of cold-work is lost at high temperatures of about $800^{\circ} \mathrm{C}$ and above (Ala-Outinen \& Oksanen, 1997 and Chen \& Young, 2006). Hence, in order to allow for this in the numerical models, the $0.2 \%$ proof strength reduction factors for temperatures of $800{ }^{\circ} \mathrm{C}$ and above were reduced by $20 \%$ in relation to those used for the sheet material provided in EN 1993-1-2 (2005) as recommended by Gardner et al. (2010). The corner strength enhancement was confined to the corner region for the press-braked sections, while for the cold-rolled sections, a uniform strength enhancement for the corner region plus an extension of $2 t$, where $t$ is the material thickness, beyond the corner radius into the flat faces of the section was used (Cruise \& Gardner, 2008).

\subsubsection{Initial geometric imperfections}

Initial geometric imperfections are introduced into structural sections during production, fabrication and handling and can significantly influence structural behaviour. Imperfection shapes of the form of the lowest global and local buckling modes obtained from a linear elastic eigenvalue buckling analysis were utilized. A global imperfection amplitude of L/2000, where L is the column total length, was adopted for the austenitic stainless steel columns, while the test measured imperfection amplitudes were used for the ferritic stainless steel columns. The amplitude predicted by the Dawson and Walker model as adapted for stainless steel (Ashraf et al., 2006), given by Eq. (3) was used for the local imperfection amplitude $\mathrm{w}_{0}$, where $\mathrm{t}$ is the plate thickness, $\sigma_{0.2}$ is the material $0.2 \%$ proof stress and $\sigma_{\mathrm{cr}}$ is the plate critical elastic buckling stress.

$\mathrm{w}_{0}=0.023 \mathrm{t}\left(\sigma_{0.2} / \sigma_{\mathrm{cr}}\right)$

\subsubsection{Analysis procedures}

Three types of numerical analyses were performed for each model - a linear elastic buckling analysis to determine the buckling mode shapes, and a heat transfer analysis to obtain the temperature development in the columns, were initially carried out. The results were subsequently incorporated into a geometrically and materially non-linear stress analysis. The non-linear stress analysis was performed in two steps to simulate the anisothermal loading condition of the column fire tests. In the first step, the load was applied to the top of the column, through its reference point, at room temperature. This load 
was maintained at a constant level during the second step while the evolution of the temperature with the fire exposure time was applied. For the case of the austenitic stainless steel columns, no heat transfer analysis were carried out, as the steel surface temperature was measured during the test and was directly imported into the models.

\subsubsection{Validation results}

A total of nine austenitic stainless steel columns and three ferritic stainless steel columns were modelled. The fire performance criteria set out in EN 1363-1 (1999) for vertically loaded members, stating that a column is deemed to have failed when both the vertical contraction and the rate of vertical contraction have exceeded $\mathrm{L} / 100 \mathrm{~mm}$ and $3 \mathrm{~L} / 1000$ $\mathrm{mm} / \mathrm{min}$, respectively, where $\mathrm{L}$ is initial column height in $\mathrm{mm}$, were used to determine the critical failure temperature. A summary of the comparison between the test and FE results is provided in Table 2. For the austenitic stainless steel columns, the FE models give a mean FE/test critical temperature of 0.90 and a coefficient of variation of 0.03 , and provide safe-side predictions of the fire resistance of the test column specimens. This under-prediction may be due to the application of uniform temperature through the thickness of the column section. In addition, all column tests were partially protected near the column ends to prevent the effect of sudden temperature variation at the start of the test, leaving a smaller exposed length than the full length used in the FE simulations. For the ferritic stainless steel columns, the FE and test results are in very good agreement with a mean $\mathrm{FE} /$ Test critical temperature of 1.01 and a coefficient of variation of 0.01 . From the comparison of the test and FE results, it is concluded that the described FE models are capable of safely replicating the non-linear, large deflection response of the stainless steel columns in fire.

\subsection{Parametric studies}

Having validated the FE models, a series of parametric studies was performed to investigate the influence of variation of global slenderness and load level on the fire performance of ferritic stainless steel columns. Two section sizes, namely SHS $80 \times 80 \times 6$ and RHS $120 \times 80 \times 6$, were employed. The same modelling procedures as explained in the previous sections were employed. The global imperfection amplitude was taken as $\mathrm{L} / 1000$, where $\mathrm{L}$ is the column length, in accordance with the permitted outof-straightness tolerance in EN 1090-2 (2008). The local imperfection amplitude was taken as that predicted by Eq. (3). All columns were pin-ended at both ends and were loaded anisothermally. Due to the symmetry in the geometry and the boundary conditions of the analyzed specimens, only half of the section, but over the full length, was modelled.
The standard ISO-834 (2002) fire curve was applied to the specimens in the heat transfer model and the temperature development was simulated through the convection, conduction and radiation heat transfer mechanisms. The length of the column specimens was varied from $0.5 \mathrm{~m}$ to $3.0 \mathrm{~m}$ in order to cover a wide range of member slenderness values. Three different load levels were applied to each column specimen: $25 \%, 45 \%$ and $65 \%$ of the room temperature minor axis buckling resistance, determined in accordance with EN 1993-1-4 (2006).

\subsection{Parametric results}

The effect of load level and member slenderness on the fire resistance of ferritic stainless steel columns, in terms of critical temperature, was studied, by fixing the cross-section size to SHS $80 \times 80 \times 6$ and RHS $120 \times 80 \times 6$. In order to focus on the member buckling behaviour, the thickness of the crosssections was chosen such that both sections are Class 1. The column lengths of $0.5 \mathrm{~m}$ to $3.0 \mathrm{~m}$ provided a range of room temperature member slenderness $\bar{\lambda}=0.25-1.55$. The obtained results are shown in Figures 3 and 4 for the SHS $80 \times 80 \times 6$ and RHS $120 \times 80 \times 6$ cross-sections, respectively. As anticipated, the column failure temperature reduces with increased load level. The variation of critical temperature with load level is also dependent on the member slenderness. This is expected as the member slenderness is dependent on the material strength and stiffness and its degradation with temperature.

\section{ANALYSIS OF RESULTS AND DESIGN RECOMMENDATIONS}

This section presents a comparison of the parametric study results with the existing design rules provided in EN 1993-1-2 (2005) and its modified versions proposed by $\mathrm{Ng}$ and Gardner (2007), Uppfeldt et al. (2008) and Lopes et al. (2010). Based on EN 1993$1-2$, the design fire resistance of stainless steel structures, assuming a uniform temperature distribution, is based on the room temperature design resistance, supplied in EN 1993-1-4 (2006), modified to take account of the mechanical properties at elevated temperature and with a revised buckling curve. Since in fire situations higher strains than at room temperature are acceptable, EN 1993-1-2 uses the elevated temperature stress at $2 \%$ total stress, $\sigma_{\mathrm{t} 2.0, \theta}$ for the design of columns with Class 1,2 and 3 cross-sections and the $0.2 \%$ proof stress $\sigma_{0.2, \theta}$ for Class 4 cross-sections. In classifying cross-sections, a reduced value for the strength parameter $\varepsilon=0.85$ $\left(235 / \mathrm{f}_{\mathrm{y}}\right)^{0.5}$ is used to allow for variation of material strength with temperature. This definition is not consistent with its room temperature definition for stainless steel defined in EN 1993-1-4 (2006) as 
Table 2. Comparison of critical temperatures between test and FE results.

\begin{tabular}{|c|c|c|c|c|}
\hline \multirow{2}{*}{$\begin{array}{l}\text { Nominal } \\
\text { section size }\end{array}$} & \multirow[t]{2}{*}{ Classification } & \multicolumn{3}{|c|}{ Critical temperature $\left({ }^{\circ} \mathrm{C}\right)$} \\
\hline & & Test & $\mathrm{FE}$ & FE/Test \\
\hline RHS $150 \times 100 \times 6$ & Class 1 & 801 & 757 & 0.91 \\
\hline RHS $150 \times 75 \times 6$ & Class 1 & 883 & 814 & 0.92 \\
\hline RHS $100 \times 75 \times 6$ & Class 1 & 806 & 744 & 0.92 \\
\hline SHS $40 \times 40 \times 4(1)$ & Class 1 & 872 & 750 & 0.86 \\
\hline SHS $40 \times 40 \times 4(2)$ & Class 1 & 579 & 502 & 0.87 \\
\hline SHS $40 \times 40 \times 4(3)$ & Class 1 & 649 & 608 & 0.94 \\
\hline SHS $40 \times 40 \times 4(4)$ & Class 1 & 710 & 646 & 0.91 \\
\hline SHS $40 \times 40 \times 4(5)$ & Class 1 & 832 & 722 & 0.87 \\
\hline SHS $40 \times 40 \times 4(7)$ & Class 1 & 766 & 681 & 0.89 \\
\hline SHS $80 \times 80 \times 3$ & Class 4 & 709 & 722 & 1.02 \\
\hline SHS $80 \times 80 \times 3$ & Class 4 & 708 & 713 & 1.01 \\
\hline RHS $120 \times 80 \times 3$ & Class 4 & 705 & 705 & 1.00 \\
\hline
\end{tabular}

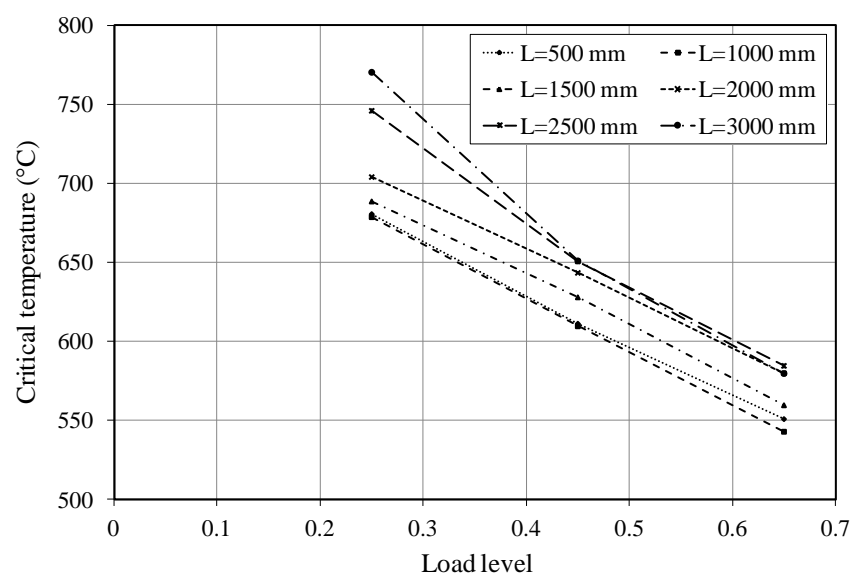

Figure. 3. Effect of load level on the SHS $80 \times 80 \times 6$ column critical temperature.

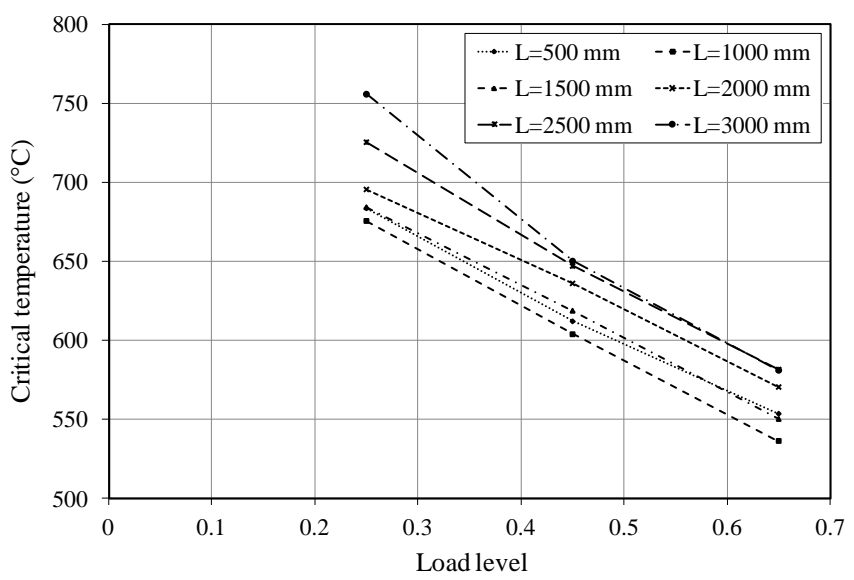

Figure. 4. Effect of load level on the RHS $120 \times 80 \times 6$ column critical temperature.

$\varepsilon=\left[\left(235 / \mathrm{f}_{\mathrm{y}}\right)(\mathrm{E} / 210000)\right]^{0.5}$. Furthermore, it does not reflect the actual variation of strength and stiffness of stainless steel at elevated temperatures. EN 19931-2 (2005) also allows the effective section properties of Class 4 sections in fire to be based on room temperature design. $\mathrm{Ng}$ and Gardner (2007) recommended that the $\sigma_{0.2, \theta}$ strength should also be used for Class 3 sections as local buckling is expected to occur prior to reaching the $2 \%$ strain limit. In addition, it was proposed that the true variation of strength and stiffness should be employed in crosssection classification and in determination of the effective section properties, leading to the $\varepsilon_{\theta}$ definitions given by Eq. (4), where $\mathrm{k}_{\mathrm{y}, \theta}$ is taken as $\mathrm{k}_{2, \theta}$ for Class 1 and 2 sections and $\mathrm{k}_{0.2, \theta}$ for Class 3 and 4 sections.

$\varepsilon_{\theta}=\left[\left(\frac{235}{\mathrm{f}_{\mathrm{y}}} \frac{\mathrm{E}}{210000}\right)\left(\frac{\mathrm{k}_{\mathrm{E}, \theta}}{\mathrm{k}_{\mathrm{y}, \theta}}\right)\right]^{0.5}$

The fire buckling curve in EN 1993-1-2 is of the same general form as the room temperature buckling curve with the exception of exhibiting no plateau (i.e. $\left.\bar{\lambda}_{0}=0\right)$, including a yield strength dependent imperfection factor $\left(\alpha=0.65\left(235 / \mathrm{f}_{\mathrm{y}}\right)^{0.5}\right)$ and defining the elevated temperature member non-dimensional slenderness, $\bar{\lambda}_{\theta}$. Ng and Gardner (2007) proposed a revised buckling curve with the plateau length $\bar{\lambda}_{0}=$ 0.2 and the imperfection factor taken as $\alpha=0.55$. Uppfeldt et al. (2008) adopted Ng and Gardner's (2007) recommendations for the cross-section classification and proposed to use the same buckling curve as room temperature, with $\bar{\lambda}_{0}=0.4$ and $\alpha=$ 0.49 (for hollow sections), for elevated temperature design, with the plateau length changing as a function of temperature, as given by Eq. (5).

$\bar{\lambda}_{0, \theta}=\bar{\lambda}_{0}\left[\frac{\mathrm{k}_{0.2, \theta}}{\mathrm{k}_{\mathrm{E}, \theta}}\right]^{0.5}$

Based on their numerical study on welded I-section columns in fire, Lopes et al. (2010) modified the EN 1993-1-2 buckling curve such that it provides a good fit to the generated data. The imperfection factor $\alpha$ is defined as a function of temperature, resulting in different buckling curves for different temperatures. Figures 5 and 6 compare the above mentioned buckling curves with an average plateau length $\bar{\lambda}_{0}=0.36$ for the investigated specimens for the Uppfeldt et al. (2008) model, and an average failure temperature of $635{ }^{\circ} \mathrm{C}$ for the Lopes et al. (2010) model with the parametric study results, where the applied load, normalized by the elevated temperature yield load based on $\sigma_{0.2, \theta}$ is plotted against the elevated temperature member slenderness.

A preliminary analysis of the results shows that the current EN 1993-1-2 (2005) buckling curve under-predicts the buckling load of ferritic stainless steel columns, while the proposals of $\mathrm{Ng}$ and Gardner (2007) and Uppfeldt et al. (2008) provide better predictions. The buckling curves proposed by Lopes et al. (2010) are considerably lower than other studies. This may be due to the section type analysed welded I-sections which do not benefit from the corner strength enhancements found in cold formed sections and have higher residual stresses. The relative performance of different section types will be considered in future work. 


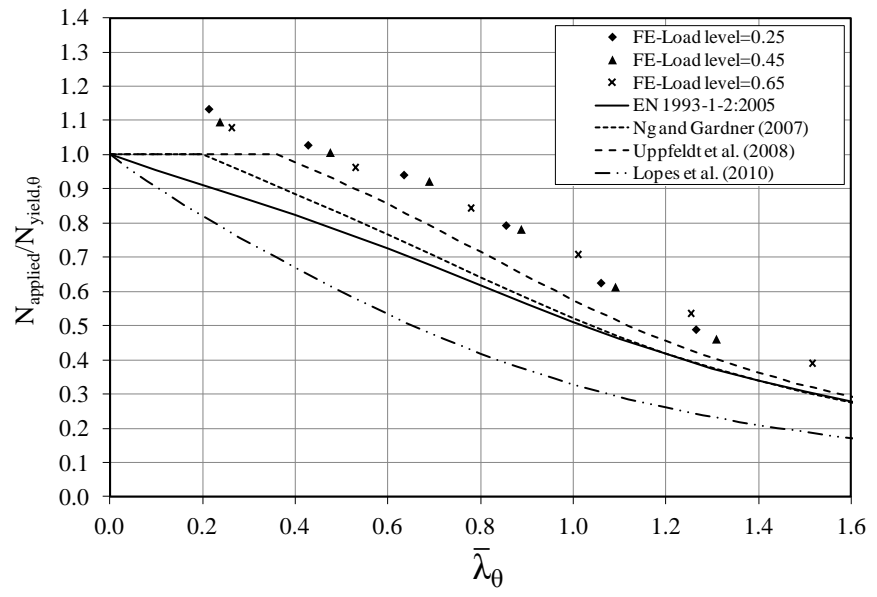

Figure. 5.Comparison of SHS $80 \times 80 \times 6$ FE results with the design models.

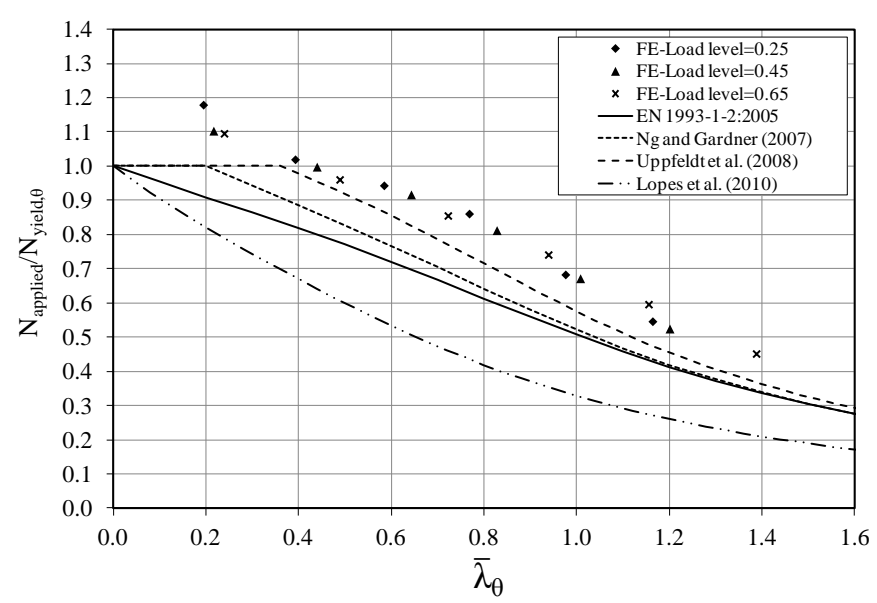

Figure. 6.Comparison of RHS $120 \times 80 \times 6$ FE results with the design models.

\section{CONCLUSIONS}

A numerical study investigating the buckling response of ferritic stainless steel columns in fire was presented. A detailed description of the finite element models was provided, which were validated against test results. The results of the parametric study, investigating the effects of variation of load level and global slenderness were presented. Comparisons between the generated data and the existing buckling curves were made.

\section{AKNOWLEDGEMENTS}

The research leading to these results has received funding from the European Community's Research Fund for Coal and Steel (RFCS) under grant agreement no. RFSR-CT-2010-00026, Structural Applications of Ferritic Stainless Steels.

\section{REFERENCES}

ABAQUS (2010) ABAQUS, Version 6.10-1. Dassault Systèmes Simulia Corp., USA.
Ala-Outinen, T. \& Oksanen, T. (1997) Stainless steel compression members exposed to fire. VTT research notes 1864. Espoo (Finland).

Ashraf, M., Gardner, L. \& Nethercot, D. A. (2006) Finite element modelling of structural stainless steel cross-sections. Thin-Walled Structures. 44 (10), 1048-1062.

Baddoo, N. R. \& Gardner, L. (2000) Member behaviour at elevated temperatures. ECSC project - Development of the use of stainless steel in construction, Contract No. 7210 SA/ 842. The Steel Construction Institute, UK, WP5.2.

Chen, J. \& Young, B. (2006) Stress-strain curves for stainless steel at elevated temperatures. Engineering Structures. 28 (2), 229-239.

Cruise, R. B. \& Gardner, L. (2008) Strength enhancements induced during cold forming of stainless steel sections. Journal of Constructional Steel Research. 64 (11), 1310-1316.

European Committee for standardization (CEN). (2005) Eurocode 3: Design of steel structures - Part 1-2: General rules - Structural fire design, EN 1993-1-2, Brussels, Belgium.

European Committee for standardization (CEN). (2002) Eurocode 1: Actions on structures - Part 1-2: General actions Actions on structures exposed to fire, EN 1991-1-2, Brussels, Belgium.

European Committee for standardization (CEN). (2006) Eurocode 3: Design of steel structures - Part 1-4: General rules -Supplementary rules for stainless steels, EN 1993-1-4, Brussels, Belgium.

European Committee for standardization (CEN). (1999) Fire resistance tests - Part 1: General requirements EN 1363-1, Brussels, Belgium.

European Committee for standardization (CEN). (2005) Stainless steels - Part 1: List of stainless steels. EN 100881. Brussels, Belgium.

European Committee for standardization (CEN). (2008) Execution of steel structures and aluminium structures - Part 2: Technical requirements for steel structures, EN 1090-2, Brussels, Belgium.

Gardner, L., Insausti, A., Ng, K. T. \& Ashraf, M. (2010) Elevated temperature material properties of stainless steel alloys. Journal of Constructional Steel Research. 66 (5), 634647.

Gmbh, S. (2011) Stahldat SX. [online] Available at: http://www.stahldaten.de [Accessed: 12 November 2012].

Lopes, N., Vila Real, P., Silva, L. S., \& Franssen, J. M. (2010) Flexural buckling of axially loaded ferritic stainless steel columns in case of fire. Journal of Structural Fire Engineering, 1(1), 43-59.

Manninen, T. \& Säynäjäkanas, J. (2012) Mechanical properties of ferritic stainless steel at elevated temperature. Proceedings of the Fourth International Experts Seminar on Stainless Steel in Structures, December 2012, The Steel Construction Institute, Ascot, UK

Ng, K. T. \& Gardner, L. (2007) Buckling of stainless steel columns and beams in fire. Engineering Structures. 29 (5), 717-730.

Rossi, B., Tondini, N. \& Franssen, J. M. (2013) Experiments on ferritic stainless steel columns in fire, to be presented at SEMC 2013.

To, E. C. \& Young, B. (2008) Performance of cold-formed stainless steel tubular columns at elevated temperatures. Engineering Structures. 30 (7), 2012-2021.

Uppfeldt, B., Ala Outinen, T. \& Veljkovic, M. (2008) A design model for stainless steel box columns in fire. Journal of Constructional Steel Research. 64 (11), 1294-1301. 